\title{
A case of Proteus syndrome (elephant man)
}

\section{MHAD De Silva1, UK Jayantha ${ }^{2}$, GK Hapuarachchi ${ }^{3}$ and GP Hewawitharana ${ }^{1}$}

(Index words: Hemihypertrophy, macrodactyly, subcutaneous tumours)

Proteus syndrome is characterised by asymmetrical growth of bones, skull, head and almost any part of the body [1].

A 10-year old boy, product of a non-consanguineous parents presented with developmental delay and poorly controlled seizures. On examination he had features suggestive of atypical growth of the body. There were asymmetric overgrowth of the skull, downward slanting of the palpebral fissures with ptosis, an epibulbar dermoid in the right eye (Figure 1) and a bony tumour (hyperostosis) of the external auditory canal of the right ear. He also had hypoplasticity of the right enamel, thick skin with epidermal naevi and megalospondylodysplasia of the spine. Right upper and lower limbs showed asymmetrical growth and soft tissue hypertrophy over the plantar surface of the right foot. A CT scan of the head showed occipital infarction and hemimegalencephaly (Figure 2).

Frequently normal at birth, the characteristic features of Proteus syndrome become obvious over the first year

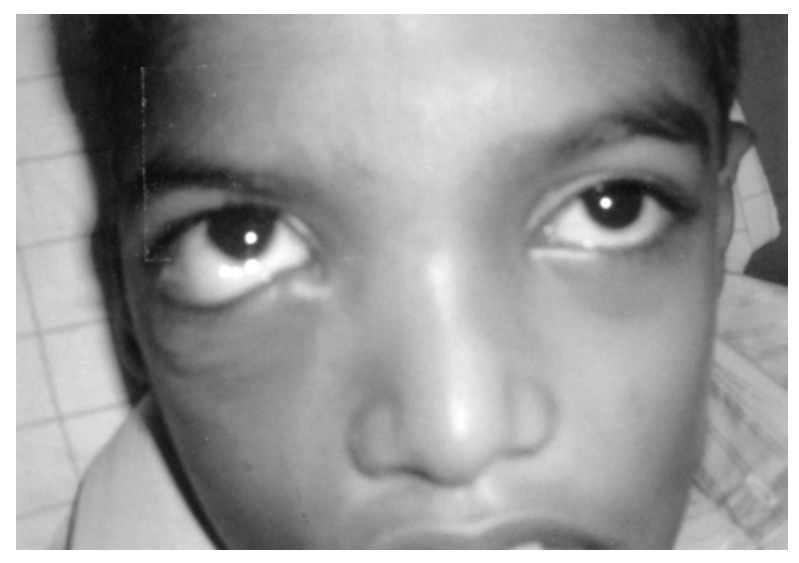

Fig.1. Epibulbar dermoid, right eye.

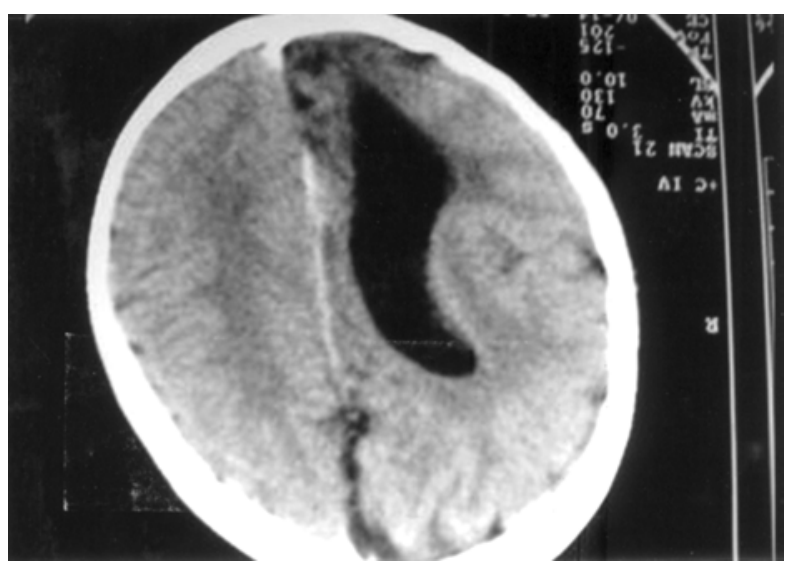

Fig.2. CT brain showing hemimegalancephaly.

of life. Generally progressive throughout childhood, growth of hamartomata and hypertrophy usually cease after puberty. Intellectual performance is usually normal. The cause of this disorder is unknown. All cases have been sporadic events in otherwise normal families. Both sexes are equally affected. There are about 120 reported cases worldwide [2]. Diagnosis is made by using the criteria given by the Proteus Syndrome Foundation $[2,3]$.

\section{References}

1. http://www.proteus-syndrome.org. Accessed on 9 April 2005.

2. Jones KL. Smith's Recognizable Patterns of Human Malformation. 4th ed. Philadelphia: Saunders, 1988: 4589.

3. Biesecker L, Happle R, Mulliken J, Weksberg R, Graham $\mathrm{Jr}$ J, et al. Proteus syndrome: diagnostic criteria, differential diagnosis, and patient evaluation. American Journal of Medical Genetics 1999; 84: 389-95.

${ }^{1}$ Registrar, ${ }^{2}$ Senior Lecturer, ${ }^{3}$ Senior Registrar, Professorial Paediatrics Unit, General Hospital (Teaching), Karapitiya, Galle, Sri Lanka.

Correspondence: MHAD de S, e-mail:<paediatrics_fom@yahoo.com>. (Competing interests: none declared). Received 7 October 2005 and accepted 18 October 2005. 